\title{
Construção sócio-histórica e midiática da velhice
}

\author{
Sandra Carolina Farias de Oliveira*, Gláucia Lorena Guedes dos Santos**
}

\section{Resumo}

Este artigo trata de uma questão que vem ganhando notoriedade nas últimas décadas: a velhice. O tema está sendo abordado principalmente nos centros de estudos e meios acadêmicos. A justificativa para isso encontra-se no crescimento exarcebado desta parcela da população. Portanto, este trabalho, num primeiro momento, tenta vislumbrar o significado e como o conceito de "ser velho" foi construído ao longo dos anos em nossa sociedade ocidental e capitalista. No segundo momento é feita uma análise de como a mídia está influenciando nesta construção, significando (ressignificando) os sentidos atribuídos aos idosos. Estudar a velhice não é uma tarefa fácil, nela estão envolvidas as ideias de finitude, pela degradação física, mental, dependência. Talvez seja por isso que o assunto ficou por tanto tempo adormecido, esquecido, pois, se a infância e a adolescência se constituem num porvir, a velhice, é considerada como o fim, sem expectativas, da qual nada se espera.

Palavras-chave: Idoso. Sociedade. Meios de Comunicação de Massa.

\section{Introdução}

Nas últimas décadas vê-se um aumento crescente das pesquisas sobre os idosos. De acordo com Prado e Sayd (2004), que realizaram um "estado da arte" das pesquisas sobre envelhecimento no Brasil através do Conselho Nacional de Desenvolvimento Científico e Tecnológico, foi constatado que as produções sobre envelhecimento estão crescendo de forma exponencial, principalmente depois do "Ano Nacional do Idoso", em 1999 (os grupos de pesquisa aumentaram em $38 \%$ aproximadamente no período de 1999-2000).

Aárea de conhecimento predominante é a da ciência da saúde e biológica, com 56,9\% de grupos de estudos sobre a temática; as ciências humanas ficam com 13,9\%. Nessas grandes áreas de conhecimento o destaque é para a saúde coletiva, com $15,3 \%$, seguida pela Medicina, $11,8 \%$, ficando psicologia em quinto lugar, com $6,9 \%$ dos grupos de pesquisas. Os grandes centros onde se encontram esses grupos são São Paulo e Rio Grande do Sul. Vale ressaltar que as três pós-

* Psicóloga. Mestra em Psicologia pela Universidade Federal de Pernambuco. Endereço para correspondência: Rua Santa Cruz do Capibaribe, 93, bairro Areias, Recife - PE. E-mail: sandrapsifarias@yahoo.com.br

** Psicóloga. Mestra em Psicologia pela Universidade Federal de Pernambuco.

$\hookrightarrow$ Recebido em junho de 2008 - Avaliado em agosto de 2009.

$\rightarrow$ doi:10.5335/rbceh.2009.041 
graduações em gerontologia estão nesses estados. Em Pernambuco concentram-se apenas 3,5\% dos grupos de estudo, em comparação com São Paulo, que lidera o ranking com $38,9 \%$.

Portanto, pode-se perceber a dimensão da preocupação com pesquisar e desenvolver novas políticas públicas que atendam a essa parcela que a cada ano vem conquistando um espaço muito grande dentro da nossa população. Uma das primordiais causas disso refere-se ao aumento da população idosa e à redução do número de nascimentos, que aos poucos derruba o slogan de o Brasil ser um país de jovens. (ZIMERMAN, 2000).

Siqueira et al. (2002) apresentaram estatísticas do IBGE sobre o envelhecimento da população brasileira, como visto nas tabelas 1 e 2 .

Tabela 1 - Porcentagem do número de idosos.

\begin{tabular}{cc}
\hline Anos & $\begin{array}{c}\text { \% de idosos da população } \\
\text { brasileira }\end{array}$ \\
\hline 1970 & 4,95 \\
1990 & 8,47 \\
2010 & $9,20^{\star}$ \\
\hline
\end{tabular}

Fonte: SIQUEIRA, R. L. et al. 2002.

${ }^{*}$ Expectativa.

De acordo com Cançado (apud SIQUEIRA, 2002), a expectativa de vida da população também cresce a cada ano:

Tabela 2 - Expectativa de vida da população.

\begin{tabular}{cc}
\hline Anos & Anos de vida \\
\hline $1950 / 1955$ & 33,7 \\
1990 & 51,0 \\
1995 & 66,3 \\
$2020 / 2025$ & $77,1^{\star}$ \\
\hline
\end{tabular}

Fonte: SIQUEIRA, R. L. et al. 2002.

${ }^{*}$ Expectativa.
É necessário ressaltar que essa importância está sendo dada no atual momento histórico e na nossa sociedade ocidental, visto que em outras culturas, ou em outras épocas, a forma como os idosos são ou foram tratados é completamente diferente.

É sobre essa temática que este artigo se propõe a dialogar. Num primeiro momento, fazendo uma reflexão sobre o conceito de velhice, vê-se que foi se modelando de acordo com o período histórico. $\mathrm{Na}$ segunda parte, de forma bastante significativa, é vislumbrada a influência da mídia no que hoje se considera "ser velho".

\section{Velhice: construção sócio-histórica?}

Para iniciar esta parte do artigo faz-se necessário expor o que estamos considerando por velhice. Esse conceito não encontra um ponto de convergência entre os autores da área. Por exemplo, Zimerman (2000), após uma pesquisa informal sobre o que é ser velho com dois grupos distintos de indivíduos - um de estudantes da área de saúde de 18 a 21 anos e o outro com mulheres de 51 a 83 anos - encontrou respostas diferentes. No primeiro grupo o velho é tido como uma pessoa chata, doente, cansada, solitária; no segundo os significados foram uma pessoa vivida, com experiência, lento, doente tranquilo e perto da morte.

Mascaro (1997) afirma que a nossa sociedade coloca dois pontos principais para demarcar a velhice: um é a própria idade cronológica e o outro, a saída do mercado de trabalho, a aposentadoria. 
Leva-se em consideração que as limitações físicas e a dependência de outras pessoas para realizar atividades corriqueiras também podem ser levadas em consideração quando se fala da velhice.

Beauvoir (1990, p. 17) afirma que "a velhice não é um fato estático; é o resultado e o prolongamento de um processo". Além disso, a autora, em seu livro $A$ velhice, referência para qualquer trabalho na área da gerontologia, concebe o ser humano como uma totalidade, de modo que ao se caracterizá-lo como velho é importante atentar para os aspectos físicos, sociais, psicológicos.

Nessa mesma perspectiva, Santana e Sena (2002) afirmam que o envelhecimento é classificado em três aspectos: biológico, psicológico e social. No primeiro é apresentada a mudança ocorrida no corpo do indivíduo, como rugas, branqueamento do cabelo, diminuição da estatura, modificações sensoriais, entre outros. No segundo são colocados o medo da morte, da solidão, como lidar com as perdas biológicas e sociais. No plano do social é tratada a rejeição do campo de trabalho e, mesmo, das relações com o outro.

Enfim, não existe um consenso sobre o que é ser velho, ou melhor, quando se começa a ser velho. Para fim de legislação, é legitimado o idoso a partir de sessenta anos em países desenvolvidos e 65 anos em países em desenvolvimento, de acordo com a OMS. No Estatuto do Idoso Brasileiro (2003) ser idoso é ter sessenta anos ou mais. Mas como esse conceito foi construído? Neri (1991, p. 18) relata:
As “idades do homem" são puras invenções sociais: o conceito de infância emergiu nos séculos XVIII e XIX, o de adolescência em fins do século XIX e o de juventude há 20 ou 25 anos atrás. $\mathrm{O}$ conceito de meia-idade como etapa intermediária entre a idade adulta e a velhice data dos anos 60. Os anos 70 assistiram à promulgação do conceito de "velhice avançada", sem dúvida um fato social e demográfico novo na história da humanidade. (ARIÈS, 1973; BADINTER, 1980; NEUGARTEN, 1979; ROSSI, 1980).

$\mathrm{Na}$ Antiguidade o valor dado aos idosos variava muito de acordo com a tribo à qual eles pertenciam. Alguns exemplos são: nas ilhas Fidji, os velhos se suicidavam por considerarem que não serviam mais para realizar qualquer que seja a atividade; entre os dinkas, a tradição era enterrar os velhos vivos; no povo ainos do Japão, eles eram deixados de lado e afastados da vida pública, assim como com os fangs e tongas; entre os hopis, índios creek e crow, bosquímanos da África do Sul, os velhos eram conduzidos a uma cabana com água e comida e lá abandonados. Esses são alguns dentre muitos casos em que geralmente o idoso não era bem quisto entre seus iguais e era morto ou abandonado. Vale salientar que isso se dava de acordo com os rituais impostos em suas tribos, muitos dos quais eram motivos de festa na comunidade. (BEAUVOIR, 1990).

É difícil apreender esses significados de um tempo tão longínquo, principalmente porque não existem muitos registros datados desse período, apenas poucas pinturas rupestres. Outro detalhe a ser levado em consideração é a desconsideração dessas civilizações de parte de sua população com as mulheres 
e escravos; nada impedia que os velhos também fossem desconsiderados. $\mathrm{O}$ número de pessoas que atingiam o que hoje pode ser considerada velhice era pouco representativo, pois a pessoas morriam muito cedo em virtude das doenças e das condições precárias de existência. Um aspecto que perpassa todas as civilizações é que apenas os velhos mais abastados social e economicamente é que eram tidos como sábios e líderes. (MASCARO, 1997).

A Idade Média também foi um período muito difícil na sobrevivência dos mais velhos. Com os feudos, quem tinha vigor físico é quem detinha o poder; muitos homens morriam jovens e era bastante raro pessoas que ultrapassassem o limite da vida adulta (os cinquenta anos). Vencendo-se essa barreira e se fossem detentores de riquezas, eram valorizados e chefes da família, ou seja, o valor não era atribuído à longevidade, mas às posses. Por sua vez, as mulheres só restavam a solidão, viuvez e a pobreza. (MASCARO, 1997).

Durante os séculos XVI a XIX os idosos continuaram sendo marginalizados, principalmente com o advento da Revolução Industrial e do capitalismo. Surgem, assim, a população do trabalho e do lucro; logo, quem não trabalha, não produz, é colocado à margem da sociedade. É o que acontece com os idosos aposentados nos dias de hoje. Essa questão está tomando proporções tão grandes que já existem programas de preparação para a aposentadoria. Sobre a questão da aposentadoria, Guidi e Moreira (1996, p. 141) definem-na: "Aposentadoria significa, pejorativamente, excluir-se, alienar-se. Em francês é retraite, cuja tradução é retiro, isolamento; em inglês é retirement, no sentido de retirada, segregação, isolamento, representando o lado negativo de parar de trabalhar.".

As autoras ainda estabelecem a relação entre a identidade do idoso e sua vinculação com o mundo social capitalista:

O lugar que a pessoa ocupa no sistema de produção reflete sua posição no sistema social, repercutindo em sua identidade [...]. É difícil a preparação para a aposentadoria. A reconstrução do cotidiano é demorada e não se processa de uma hora para outra. A aposentadoria causa uma fratura na interação social. (p. 146).

Nos dias de hoje, ainda se pode perceber a grande influência dessa forma de pensar o homem como aquele que trabalha. Mas é importante enxergar uma nova tendência, que é ver o homem como aquele que consome, que compra. É por essa razão que os idosos vêm se tornando alvo das propagandas e a cada dia um novo produto para esta faixa etária é lançado. Neste ponto de nossa discussão entramos no próximo tópico, que se relaciona com a mídia.

\section{Influência da mídia na apreensão dos significados da velhice}

Assim como foi necessário fornecer uma conceituação do que é velhice, faço uma explanação do conceito de mídia e mercado de consumo. A mídia, nos dias de hoje, assume uma influência significativa dentro da nossa sociedade. Souza, (2005) afirma que nossa vida de relações é construída nos intervalos dos programas de TV. Vale salientar que a 
mídia da qual falamos é a televisiva, alcança uma maior parcela da população, de variadas idades e níveis socioeconômicos. É interessante saber que a própria mídia faz essas categorizações e cria as necessidades de consumo delas. (BEZERRA, 2006).

Atrelada à ideia de mídia está o de meios de consumo, que desde a Revolução Industrial dita regras à nossa sociedade. Como diz Souza (2005), hoje o que reina entre nós é a cultura do consumo, a produção de desejo e a efemeridade dos objetos e relações. Então, pode-se dizer que as pessoas hoje não representam $o$ que elas são, e sim o que possuem ou podem comprar. É nesse sistema que o idoso, assim como as outras classes etárias, está inserido no sistema do consumismo difundido por uma mídia, no qual a lei é vender.

Focando no tema do artigo Debert, (2004, p. 33) afirma: "A velhice é uma construção sociocultural." Sendo a nossa sociedade pautada pela globalização e um meio de comunicação rápido e eficiente, não poderíamos deixar de falar na influência da mídia na imagem que é veinculada sobre a velhice nos dias de hoje. Além disso, podendo-se falar em idosos como um público consumidor significativo nas últimas décadas, percebese uma modificação na programação da mídia em razão dessa nova parcela da população. De acordo com AcostaOrjuela:

O tamanho da audiência da TV, sua abrangência geográfica, sua dimensão econômica e suas perspectivas de expansão são de proporções não conhecidas antes por nenhum outro meio de comunicação. Tais antecedentes explicam em parte por que leigos e cientistas vêem com preocupação a quantidade de informação que o meio vincula, o alto grau de realismo que consegue imprimir, a multiplicação desenfreada de modelos de comportamento, a alta freqüência de conteúdos violentos, estereotipados e sensacionalistas, seu excessos publicitários, o uso político-ideológico do meio, seu impacto transcultural sobre valores, costumes e tradições [...]. Onde funciona sob um modelo comercial. (Apud NERI; DEBERT, 1999, p. 181).

A importância atribuída às categorias etárias bastante difundidas por este meio de comunicação, que, se não for bem administrado para o bem da população, pode causar grandes danos, principalmente no que diz respeito aos valores culturais de nossa população. Para exemplificar, de acordo com Leite (2003, p. 7-8), pode-se falar na figura do idoso de algumas décadas atrás, que era sempre associada a um medicamento com promessas de prolongar a vida, ou a uma imagem pejorativa (tristeza, dependência, doença), ao passo que nos dias de hoje

nossos idosos de "alma jovem" seriam tão somente vítimas do mercado que os quer moldar para a soberba ilusão do consumo, negação da morte, desmerecimento do estatuto de testemunhas da história, enfim, festejar, festejar e festejar a glória dos recursos tecnos-científicos, otimizando o organismo para uma grande festa rave da melhor idade, sem data para terminar, todos juntos, curtindo uma onda eletrônica isolada e hipnótica, munidos com celulares fluorecentes para melhor varar a noite e saber das novas baladas.

Portanto, percebe-se que existe uma utopia quando se fala em velhice nos dias de hoje. Até mesmo nos termos utilizados 
para nomear esta fase da vida procuramse palavras que não carreguem sentidos que possam ser pejorativos, como de velho: "idoso", "melhor idade", "terceira idade". Os asilos são tidos hoje como "centros para idosos".

É nesse sentido que se encontra o perigo nas informações passadas pela mídia. Perigo em corroborar com uma imagem fantasiosa de velhice, favorecendo o que Bevouir, (1990) e Debert (2004) chamam de "conspiração do silêncio". Na mídia de hoje a velhice é vista principalmente de forma positiva, dificultando a elaboração de uma velhice realista, vista sob os aspectos positivo e negativo. Nessa idealização da velhice leva-se os idosos a se afastarem de temas ditos como interditos, como, por exemplo, a própria limitação física e a morte.

\section{Conclusão}

Percebe-se, claramente, que a população idosa merece um destaque no meio acadêmico e sociocultural, não apenas por ser uma faixa etária de crescimento acelerado nas últimas décadas, mas por ser uma parcela da população que precisa de um olhar diferenciado para atender a suas necessidades. Sendo a velhice, ou terceira idade, uma construção social da nossa sociedade, passou por transformações, desde a Antiguidade, quando os velhos eram em número reduzido e apenas os ricos eram privilegiados, até os dias de hoje, quando um paradoxo se instala entre a terceira idade e o velho, seguindo a mesma lógica da Antiguidade, os ricos e pobres, respectivamente. O mercado consumidor, outrora denominado trabalho, representado pela mídia, que domina nossa sociedade nos dias atuais, está com o olhar voltado para um grande consumidor: o velho.

Old age's historic-social and mediatic construction

\section{Abstract}

This article is about a question that gained notoriety in the last decades: the old age. This theme is being boarded mainly in studies centers and academics spaces. The justification for that is found in the growth of this population. So, first this article tries to find the meaning and ways the concept of "being old" was constructed at our western and capitalist society. After, we will analyze how the media is influencing that construction, signifying and re-signifying the meanings attributed to old age persons. Studying old age isn't an easy task, because it involves ideas of finitude, physical and mental degradation, dependency. That is, maybe, the reason why such subject laid quiet for so long, even forgotten, because childhood and adolescence are a future, while old age was considered an end, without expectations, where nothing was expected.

Key words: Old age. Society. Mass Media.

\section{Referências}

BEAUVOIR, S. A velhice. 3. ed. Rio de Janeiro: Nova Fronteira, 1990.

BEZERRA, A. K. G. A construção e reconstrução da imagem do idoso pela mídia televisiva. Campina Grande: UFCG, 2006. Disponível em: <www.bocc.ubi.pt/ bocc/_esp/ autor.php3?codautor $=898>$. Acesso em: 18 jul. 2006.

BRASIL. Ministério da Saúde. Estatuto do Idoso. 1. ed. 2. reimp. Brasília: Ministério da Saúde, 2003. 
DEBERT, G. G. A Reinvenção da velhice: socialização e processos de reprivatização do envelhecimento. São Paulo: USP/Fapesp, 2004.

GUIDI, M. L. M.; MOREIRA, M. R. L. P. Rejuvenescer a velhice: novas dimensões da vida. 2. ed. Brasília: UnB, 1996.

LEITE, E. F. Adolescência e velhice: um comentário desde a mídia contemporânea. Congresso Internacional Co-Educação de Gerações. Sesc - São Paulo: 2003. Disponível em: <www.sescsp.org.br/sesc/images/upload/ conferencias/91.rtf>. Acesso em: 22 jun. 2006.

MASCARO, S. A. O que é velhice. São Paulo: Brasiliense, 1997.

NERI, A. L. Envelhecer num país de jovens: significados de velho e velhice segundo brasileiros não idosos. São Paulo: Unicamp, 1991.

NERI, A. L.; DEBERT, G. G. (Org.). Velhice e sociedade. São Paulo: Papirus, 1999.

PRADO, S. D.; SAYD, J. D. A pesquisa sobre envelhecimento humano no Brasil: grupos e linhas de pesquisa. Ciência \& Saúde Coletiva, Rio de Janeiro, v. 9, n. 1, p. 57-67, set. 2004. Disponível em: <www.scielosp.org/ scielo.php?script=sci_arttext\&pid=S1413$81232004000100006 \& \operatorname{lng}=$ en $\& \mathrm{nrm}=\mathrm{iso}>$. Acesso em: 23 maio 2006. DOI: 10.1590/ S1413-81232004000100006.

A pesquisa sobre envelhecimento humano no Brasil: pesquisadores, temas e tendências. Ciência \& Saúde Coletiva, Rio de Janeiro, v. 9, n. 3, p. 763-772, set. 2004. Disponível em: <www.scielosp.org/ scielo.php?script=sci_arttext\&pid=S1413$81232004000300027 \& \operatorname{lng}=$ pt\&nrm $=$ iso $>$. Acesso em: 23 maio 2006. DOI: $10.1590 /$ S1413-81232004000300027.

SANTANA, H. B.; SENA, K. L. Repensando a $3^{\underline{a}}$ idade: um novo olhar sobre o envelhecer. Recife: UFPE, 2002.

SIQUEIRA, R. L. et al. A velhice: algumas considerações teóricas e conceituais. Ciência \& Saúde Coletiva, Rio de Janeiro, v. 7, n. 4, p. 899-906, 2002. Disponível em: <www.scielosp.org/scielo.php?script=sci arttext\&pid=S1413-81232002000400021\&ln $\mathrm{g}=$ pt\&nrm=iso $>$. Acesso em: 8 jul. 2006. DOI: 10.1590/S1413-81232002000400021.

SOUZA, S. J. et al. Subjetividade em questão: a infância como crítica da cultura. 2 . ed. Rio de Janeiro: 7 Letras, 2005.

ZIMERMAN, G. I. Velhice: aspectos biopsicossociais. Porto Alegre: Artmed, 2000. 